\title{
Structural Design and Analysis of 1U Standardized STEP Cube Lab for On-Orbit Verification of Fundamental Space Technologies
}

\author{
Hyun-Ung Oh, Su-Hyeon Jeon, and Seong-Cheol Kwon
}

\begin{abstract}
The STEP Cube Lab (Cube Laboratory for Space Technology Experimental Projects) is a 1U cube satellite developed by the Space Technology Synthesis Laboratory of Chosun University to be launched in 2015. Its mission objective is twofold: to determine which of the fundamental space technologies researched at domestic universities, will be potential candidates for use in future space missions and to verify the effectiveness of the technologies by investigating mission data obtained from on-orbit operation of the cube satellite. In this paper, a structural design concept based on the $1 \mathrm{U}$ standard to achieve the mission objective is introduced. The validity of the design has been demonstrated by quasi-static analysis and modal analysis. In addition, a non-explosive separation device triggered by burn wire heating, which is one of the main mission payloads is introduced.
\end{abstract}

Index Terms - CubeSat, pico-class satellite, structural design, non-explosive separation mechanism.

\section{INTRODUCTION}

The program of pico-class satellites called CubeSats started in 1999 at the space systems development laboratory (SSDL) at Stanford University under the leadership of Robert J. Twiggs [1]. The main purpose of CubeSats is to make space science and technology readily accessible to students, engineers, and even to some governments at a fraction of the design, build, and launch costs of standard satellite projects [2]. The main features of the CubeSat is $10 \mathrm{~cm} \times 10 \mathrm{~cm} \times 10 \mathrm{~cm}$ in volume and less than $1.33 \mathrm{~kg}$ in mass based on the $1 \mathrm{U}$ CubeSat standard.

The STEP Cube Lab (Cube Laboratory for Space Technology Experimental Project) is the first pico-class satellite developed at the STSL (Space Technology Synthesis Laboratory) at Chosun University, and is scheduled to be launched in 2015. The main mission objective of the STEP Cube Lab is twofold: to determine which fundamental space technologies researched at domestic universities, will be potential candidates for future space missions and to verify the effectiveness of these technologies by investigating mission data obtained from on-orbit operation of the cube satellite. The function and performance of these technologies have been previously verified by laboratory-level research at

Manuscript received January 27, 2014; revised March 24, 2014. This research was supported by Space Core Technology Development Program through the National Research Foundation of Korea funded by the Ministry of Science, ICT \& Future Planning.

The authors are with the Department of Aerospace Engineering, Chosun University (e-mail: ohu129@chosun.ac.kr, fifa2684@naver.com, mine1147@hanmail.net). universities, but their design effectiveness has never been qualified in environment of outer space or in some cases, on-ground simulated space environment. Therefore, we cannot guarantee that these technologies will operate without any malfunction in an on-orbit environment although they showed stable function during laboratory-level tests. The STEP mission makes it possible to perform on-orbit verification of five technologies using a $1 \mathrm{U}$ CubeSat. The payloads to be verified in the STEP mission are a variable emittance radiator, an oscillating heat pipe, a MEMS based solid propellant thruster, a concentrating photovoltaic (CPV) power system, and a novel non-explosive holding and release mechanism triggered by nichrome burn wire heating.

In this paper, we focus on the non-explosive holding and release mechanism triggered by a nichrome burn wire, which is one of the main payloads to be verified in the STEP mission, because it is most closely related to the mechanical design. This mechanism will be applied to achieve synchronous release of multi-deployable communication antennas using a single mechanism in the STEP mission. The mechanism has the advantage of negligible induced shock and greater load capability than conventional nylon cable cutting mechanisms [3] that are generally used in cube satellite applications. This mechanism also enables synchronous release of multiple deployable structures when an appropriate implementation method is used.

A pyro technic device [4] is also a candidate for complex cube missions in which greater load capability is required. However, usage of pyrotechnic devices in a cube satellite may cause problems because the external and internal parts are in closer physical proximity to the source of shock in a cube satellite than in larger commercial satellites, owing to the extremely small size and volume of a cube satellite. Additionally, the cube satellite requirements do not permit the use of explosive pyrotechnic devices.

Several types of non-explosive separation device using shape memory alloys [5] have been developed and used in space missions. The advantages of the non-explosive actuators are lower shock, greater load capability, and reusability for additional cycles after a simple reset. However, even though the shock level is low, use of these devices in cube satellites may nevertheless be limited because of their high cost and the fact that they do not meet the typical pico-satellite requirements of low weight, small size, and generating relatively small shocks. The high cost of these devices makes them impractical to use on cube satellites that have development cost limitations.

In this study, a structural design concept of the STEP Cube 
Lab to achieve the mission objectives is proposed and investigated. The design concept is based on a standardized $1 \mathrm{U}$ cube design, and it will fly a number of payloads for on-orbit verification of technology for future missions. For the $1 \mathrm{U}$ CubeSat design, it is very important to achieve an efficient lightweight satellite configuration under the constraints of limited volume. The structural design combined with a novel non-explosive holding and release mechanism used for synchronous release of multi-deployable antennas is described in this paper. The effectiveness of the structural design has been verified using quasi-static and modal analysis In addition, the margin of safety for the PCBs with respect to the estimated allowable deflection has been investigated based on fatigue failure theory.

\section{STEP MisSION PAYLOADS AND FEATURES OF THE NON-EXPLOSIVE HOLD AND RELEASE MECHANISM}

In general, owing to the high development cost of space qualification of research output, research on advanced space technologies for future missions performed at universities is limited to theoretical works and laboratory-level research without consideration of the space environment. Therefore, the main mission objectives of the STEP Cube Lab are to identify core space technologies researched in industries or universities, and to verify these technologies on-orbit.

Table I summarizes the payload candidates to be verified in the STEP mission. The MEMS solid propellant thruster [6] comprises a micro-nozzle, a micro-igniter, a glass membrane, a propellant chamber, and a solid propellant. The average values of the maximum thrust and total impulse are $3619 \mathrm{mN}$ and $0.381 \mathrm{mNs}$, respectively. The thruster is suitable for cube satellite applications because it consumes less than $300 \mathrm{~mW}$ for ignition of the solid propellant.

Variable emittance radiators [7] based on the metal-insulator transition of $(\mathrm{La}, \mathrm{Sr}) \mathrm{MnO}_{3}$ thin films have been developed. The ( $\mathrm{La}, \mathrm{Sr}) \mathrm{MnO}_{3}$ thin films have low emittance at low temperature and high emittance at high temperature. Moreover, the emittance significantly changes at the metal-insulator transition temperature, at which the material changes from a highly reflective metal into a less reflective insulator. Therefore, in the case of the lowest temperature, the radiator does not require additional heater power to keep the electronics within the allowable non-operating cold temperature.

Commonly used heat pipes, which achieve promising heat transfer performance using surface tension and capillary action, experience performance degradation during ground test due to the gravity effect when the heat pipes are inclined. To overcome the disadvantages of conventional heat pipes, oscillating heat pipes [8] have been proposed and investigated Oscillating heat pipes uses the phenomenon of self-sustaining oscillatory flow of working fluid. Heat is transferred in the liquid-vapor circulation cycle between the heating section and the cooling section as latent heat. Therefore, particularly regarding ground tests, oscillating heat pipes are useful in satisfying the mechanical design constraints of satellites because the performance degradation of the heat pipe due to gravity can be minimized.
A CPV power system [9] is a photovoltaic power generation system that uses a small generating device to convert energy from high intensity light from the sun that has been concentrated by a lens array system. CPV systems have been widely used for ground applications because there is no restriction on the size of the lens system. However, CPV technology has not been considered for space applications although effective power generation is expected. Therefore, we focus on a CPV system for cube satellite applications that uses a MEMS based lens array system. This system has the potential to increase power generation when the $\beta$ angle between the sunlight and the solar cell is zero by effectively concentrating solar energy on solar panels.

TABLE I: PAYLOADS OF STEP CUBE LAB

\begin{tabular}{|c|c|c|c|}
\hline Payload & Configuration & Payload & Configuration \\
\hline $\begin{array}{l}\text { MEMS } \\
\text { Solid } \\
\text { Propellant } \\
\text { Thruster }\end{array}$ & & $\begin{array}{l}\text { Oscillating } \\
\text { Heat pipe }\end{array}$ & \\
\hline $\begin{array}{l}\text { Variable } \\
\text { Emittance } \\
\text { Radiator }\end{array}$ & & $\begin{array}{l}\text { MEMS } \\
\text { CPV } \\
\text { System }\end{array}$ & 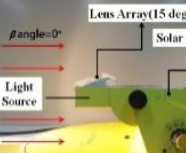 \\
\hline
\end{tabular}

*Non-explosive holding and release mehcanism is described in Fig. 1

Recently, cube satellites have been used for increasingly complex missions. Considering their extremely small package size, the range of functions that they can perform gives rise to the use of numerous mechanisms and deployable structures that are necessary for achieving challenging mission-related functions. The cube satellite architecture also requires that deployable structures, such as solar arrays, antennas, and other appendages, are stowed for launch, and released and deployed in orbit for operation. To hold and release deployable appendages of a cube satellite, a nichrome burn wire release mechanism has typically been used owing to its advantages of being simple, reliable, and inexpensive. However, if we apply this conventional mechanism to applications with multi-deployable appendages, the systems of a cube satellite may be complicated by the many nichrome burn wire release mechanisms required for holding multi-deployable structures. The conventional mechanism using nylon wire also has drawbacks such as complexity and low constraint force. To overcome these drawbacks, we developed a non-explosive holding and release mechanism based on the nylon cutting method as one of the payloads for the STEP missions. This mechanism was designed for high load capacity, negligible shocks, and synchronous release of multi-deployable structures. Figure 1 shows both the stowed and released configurations of the non-explosive separation mechanism. The mechanism consists of a constraint bolt, two segmented nuts, a pin, a nylon cable, and two springs. Both springs are compressed inside of the separation nut, and this nut is constrained by winding the nylon cable around it. The nut is released by triggering the nichrome burn wire. When the nichrome burn wire is heated, the nylon cable wound around the integrated nut is cut, and the nut is immediately separated by the restoration force of the two springs, as shown 
in Fig. 1(b). The springs allow the release of the constraint bolt when the segments of the separated nut rotate away from the bolt around the pin at the bottom of the mechanism. The nichrome wire is positioned on the $\mathrm{V}$-shaped interface and is located far away from the mechanism's heat sinks to avoid heat loss and ensure a successful cut. The nichrome wire is also reciprocally woven in a zigzag line through the nylon cable, as shown in Fig. 1(a). This guarantees reliable cutting through the cable by avoiding poor contact between the nichrome burn wire and the cables, which can be caused by a decrease in the cable tension due to partial cutting of the cable.

Fig. 2 shows an example of a successful release sequence of the mechanism after triggering the nichrome burn wire at the lower limit of the qualification temperature range of $-20^{\circ} \mathrm{C}$. The images indicate that the separation is successfully completed within $5 \mathrm{~s}$ after triggering by the nichrome burn wire heating, without any interference from the constraint bolt during the release sequence.

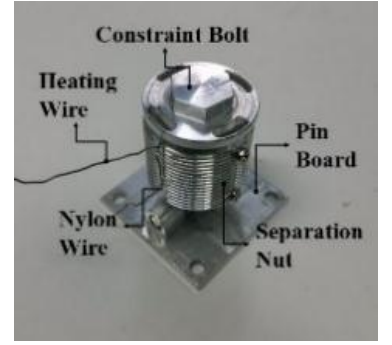

(a) Holding State

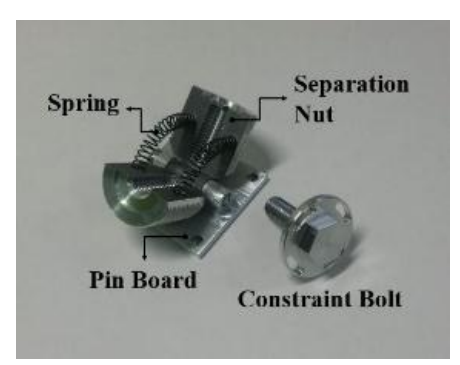

(b) Release State
Fig. 1. Non-explosive holding and release mechanism.

\section{STRUCTURE DESIGN OF THE STEP CUBE LAB}

The purpose of the structural design is to provide adequate strength and stiffness to ensure the survival of the STEP Cube Lab under launch and orbital conditions during all phases of the mission. The structural design of the STEP Cube Lab meets the structural requirements derived from the mission requirements and the $1 \mathrm{U}$ cube satellite standard.

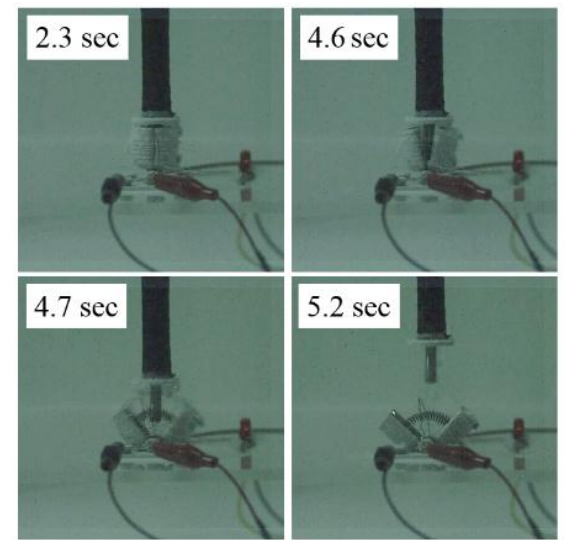

Fig. 2. Sequence of holding and release mechanism activation.

Fig. 3(a) and (b) shows the stowed and deployed configurations of the STEP Cube Lab in launch and on-orbit conditions, respectively. The structure is composed of an upper panel module structure and a service module structure, as shown in Fig. 3(b). The upper panel module structure is fixed to the service module structure by the non-explosive holding and release mechanism and four turnstile antennas are fixed by the dedicated brackets attached to the $+Z$ panel of the upper panel module. When current is sent through the nichrome burn wire, the release mechanism is activated, and the upper cube module with the antenna-holding brackets is deployed by the restoration force of the springs compressed inside the longeron beams. The antennas are subsequently released and automatically deployed, as shown in Fig. 3(b). The synchronous release of the four turnstile antennas is implemented by a single mechanism, in contrast to the four activation mechanisms required for the burn wires in the conventional method. The holding and release mechanism constrains displacement of the upper cube module in the out-of-plane direction to ensure the structural safety of the satellite during lift-off. Constraint in the in-plane direction is provided by a longeron interface with an in-plane mechanical displacement limitation, as shown in Fig. 3. The mechanism proposed in this study to constrain both out-of-plane and in-plane movement combines a ball-and-socket interface or a longeron interface as shown in Fig. 3 and it can be adapted for various applications.

Fig. 4 shows the internal configuration of the satellite. The mission boards, including the on-board computer, EPS, communication, and GPS boards are positioned on the service module structure. The variable emittance radiator is located on the $+Z$ panel and the reference radiator with fixed emissivity is attached near the variable emittance radiator to confirm the effectiveness of changing the thermal characteristics of the radiator by varying emissivity with temperature variation on-orbit. The other mission payloads, the oscillating heat pipe and the holding and release mechanism, are located on the middle panels, which are made of Al-6061. The permanent magnet and hysteresis damper for permanent magnet attitude stabilization are also positioned in the same panels for optimal uses of space.

The MEMS based solid propellant thruster combined with the thruster control board is placed on the bottom side of the structure, as shown in Fig. 5 for easier access to the MEMS thruster during the integration and test phases.

The CPV lens array assemblies are positioned on the side solar panels at an angle of 15 degrees to effectively concentrate solar energy onto the solar panels when the $\beta$ angle between the sunlight and the solar panels is zero, which is the worst-case condition for solar power generation.

Table II summarizes the estimated mass budget of the satellite. The total mass of all of the components is $0.969 \mathrm{~kg}$ and $0.361 \mathrm{~kg}$ margin is guaranteed with respect to the mass limitation of $1.33 \mathrm{~kg}$ of a $1 \mathrm{U}$ cube satellite.

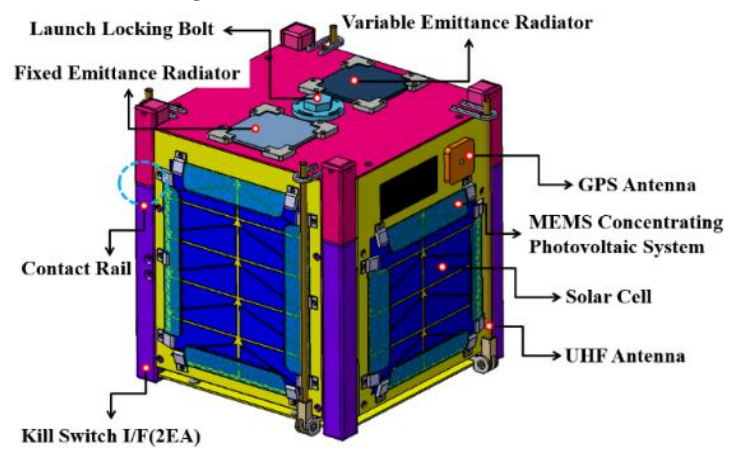

(a) Launch Configuration 


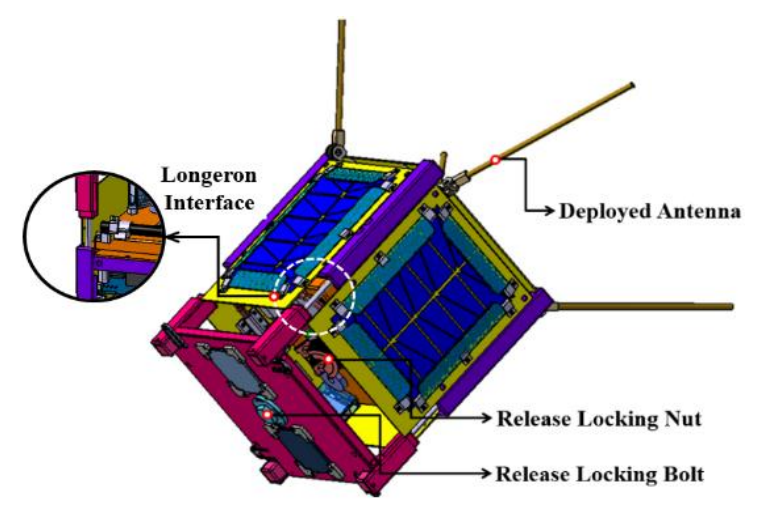

(b) Deployed Configuration On-orbit

Fig. 3. STEP Cube lab configuration.

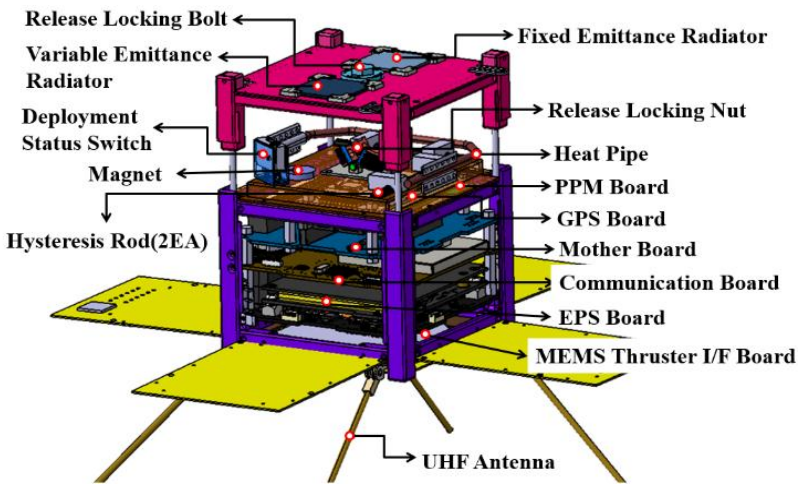

Fig. 4. Internal configuration of STEP Cube lab.

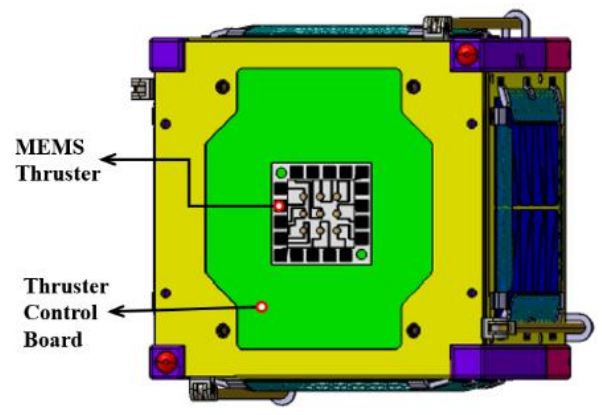

Fig. 5. MEMS thruster location.

TABLE II: MASS BUdGET OF STEP CUBE LAB

\begin{tabular}{l|l}
\hline \hline Components & Mass $(\mathrm{kg})$ \\
\hline Structure & 0.32 \\
\hline Mechanism & 0.019 \\
\hline Electronic Boards & 0.368 \\
\hline AOCS & 0.035 \\
\hline Payloads & 0.156 \\
\hline Etc. & 0.071 \\
\hline Total Mass & 0.969 \\
\hline Margin (w.r.t. Req. of $1.33 \mathrm{~kg})$ & 0.361 \\
\hline \hline
\end{tabular}

\section{STRUCTURAL ANALYSIS AND RESUlTS SUMmaRy}

To confirm the effectiveness of the structural design of the $1 \mathrm{U}$ cube satellite STEP Cube Lab, quasi-static analysis to confirm the margin of safety with respect to the design load, modal analysis to confirm that the frequency requirement was satisfied, and PCB analysis to confirm the margin of safety with respect to the allowable deflection of the PCBs were performed using a simplified finite element model (FEM) as shown in Fig. 6.
For the analysis, MSC Patran software was used for preand post-processing and MSC-Nastran was employed as a solver. Table III summarizes the material properties used in the analysis. The frame structures of the primary structure of the cube satellite are modeled by using 1D beam elements. The PCB connections are also modeled using 1D beam elements. Shell elements were used to represent each of the structure panels, the PCBs, the MEMS concentrating lens, and the MEMS thruster. The non-explosive holding and release mechanism was modeled using spring elements with an axial stiffness of $4170 \mathrm{~N} / \mathrm{mm}$, based on a static test. In the analysis, rigid boundary conditions were applied at the bottom sides of the beam structures.

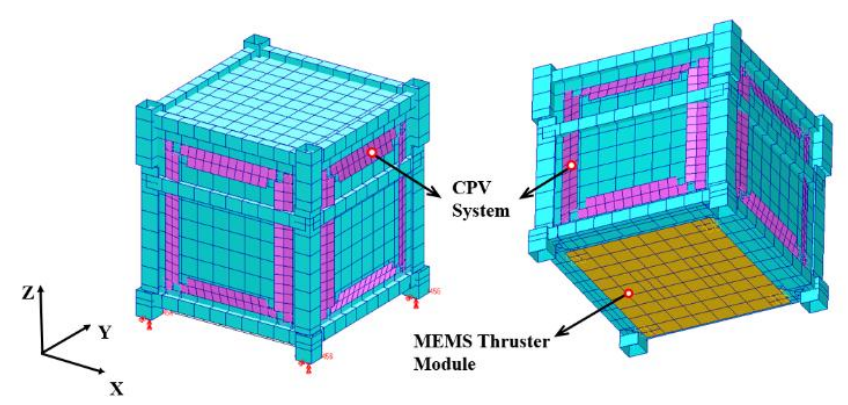

(a) Primary Structure

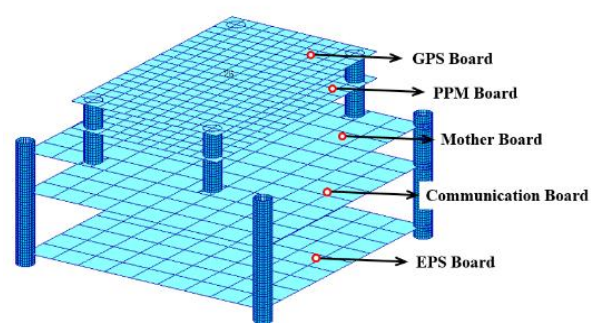

(b) PCBs

Fig. 6. FEM of STEP Cube lab.

TABLE III: MATERIAL PROPERTIES

\begin{tabular}{l|l|l|l|l|l}
\hline \hline & $\begin{array}{l}\text { Density } \\
\left(\mathrm{kg} / \mathrm{m}^{3}\right)\end{array}$ & $\begin{array}{l}\text { Yong's } \\
\text { Modulus } \\
(\mathrm{GPa})\end{array}$ & $\begin{array}{l}\text { Poisson's } \\
\text { Ratio }\end{array}$ & $\begin{array}{l}\text { Yield } \\
\text { Stress } \\
(\mathrm{MPa})\end{array}$ & $\begin{array}{l}\text { Ultimate } \\
\text { Stress } \\
(\mathrm{MPa})\end{array}$ \\
\hline $\begin{array}{l}\text { PCB } \\
\text { (Polyimide) }\end{array}$ & 1850 & 18.37 & 0.136 & - & 242 \\
\hline $\begin{array}{l}\text { Structure } \\
(\text { Al6061-T6) }\end{array}$ & 2700 & 68.9 & 0.33 & 276 & 310 \\
\hline $\begin{array}{l}\text { CPV, } \\
\text { MEMS } \\
\begin{array}{l}\text { Thruster } \\
\text { (Glass })\end{array}\end{array}$ & 2370 & 77.8 & 0.22 & 70 & 70 \\
\hline \hline
\end{tabular}

To verify compliance with the frequency requirement, we performed a modal analysis. The required first eigen frequency for frequency separation during launch is larger than $100 \mathrm{~Hz}$. The modal analysis results are summarized in Table IV, and the mode shapes of interest are shown in Fig. 7. The calculated the first eigen frequency is $155 \mathrm{~Hz}$ for the bending mode of the PCB modules, as shown in Fig. 7, which is greater than the requirement of $100 \mathrm{~Hz}$. The modes until twelve modes are observed from the local modes of the PCBs. The modes of involving the CPV lens array module occurred at a frequency of $622.85 \mathrm{~Hz}$, and is well decoupled from the eigen frequency of approximately $1000 \mathrm{~Hz}$ of the primary structural mode of the longeron beams, although this is not 
shown here because the CPV lens system is directly integrated into the longeron beams through the solar panels.

To investigate structural safety under the launch environment, we performed a quasi-static analysis. For this analysis, we applied a design load of $g=42.3 \mathrm{G}$ derived from the qualification level of a random vibration of $14.1 \mathrm{Grms}$, as shown in the following equation.

$$
g=14.1 G r m s \times 3 \sigma
$$

To investigate structural safety, we applied the following MoS (Margin of Safety) rule with a safety factor of 1.25.

$$
M o S=\frac{\sigma_{\text {allowable }}}{S F \times \sigma_{\max }}-1 \geq 0
$$

Here, $\sigma_{\text {allowable }}$ is the allowable strength, $\sigma_{\max }$ is calculated strength and SF is the safety factor. For the PCB and the glass materials, safety factors of 1.4 and 2 were applied in the analysis, respectively. Table $\mathrm{V}$ summarizes the maximum stress and MoS at each axis under a quasi-static load of $42.3 \mathrm{G}$ The analysis results indicated sufficient margins in all cases and in all directions. The CPV system also showed a positive margin in all directions, although it is brittle material with a low allowable strength compared to other parts.

TABLE IV: MODAL FREQUENCIES

\begin{tabular}{l|l|l|l|l|l}
\hline \hline Mode & $\begin{array}{l}\text { Frequency } \\
(\mathrm{Hz})\end{array}$ & $\begin{array}{l}\text { Zone of } \\
\text { Interest }\end{array}$ & Mode & $\begin{array}{l}\text { Frequency } \\
(\mathrm{Hz})\end{array}$ & $\begin{array}{l}\text { Zone of } \\
\text { Interest }\end{array}$ \\
\hline 1 & 155.21 & PCB & 8 & 521.4 & PCB \\
\hline 2 & 161.1 & PCB & 9 & 593.85 & PCB \\
\hline 3 & 271.22 & PCB & 10 & 600.02 & PCB \\
\hline 4 & 275.2 & PCB & 11 & 610.4 & PCB \\
\hline 5 & 283.53 & PCB & 12 & 616 & PCB \\
\hline 6 & 331.04 & PCB & 13 & 619.25 & $\begin{array}{l}\text { MEMS } \\
\text { Thruster }\end{array}$ \\
\hline 7 & 435.17 & PCB & 14 & 622.85 & CPV \\
\hline \hline
\end{tabular}

To investigate the structural safety of the PCB electronics under the launch environment, we performed PCB analysis based on fatigue failure theory. Figure 8 shows an example of the EPS board configuration considered in the analysis. The allowable deflection of the PCB is calculated using following equation (3) and the PCB configuration shown in Fig. 8.

$$
\delta_{\text {allowable }}=\frac{0.0028 d}{C t r l^{0.5}}
$$

Here, $d$ is the length of the PCB edge parallel to the component, $C$ is the coefficient of chip configuration, $t$ is thickness of the PCB, $l$ is the length of the component, and $r$ is derived from the component's position [10]. To investigate structural safety, we applied the following MoS rule with a safety factor of 1.4 .

$$
M o S=\frac{\delta_{\text {allowable }}}{S F \times \delta_{\max }}-1 \geq 0
$$

Here, $\delta_{\text {allowable }}$ is the allowable deflection, $\delta_{\max }$ is the calculated maximum deflection, and $S F$ is the safety factor. Table IV summarizes the MoS results for the PCBs with respect to their maximum allowable deflection of PCBs. The analysis results indicate that all cases showed positive margins in the critical axis of $z$ from a PCB structural safety point of view. The analysis results indicate that the structure design of $1 \mathrm{U}$ standardized STEP Cube Lab guarantees structural safety in the launch environment.

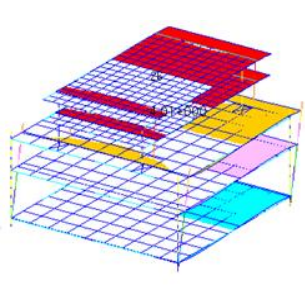

(a) $1^{\text {st }}$ Mode

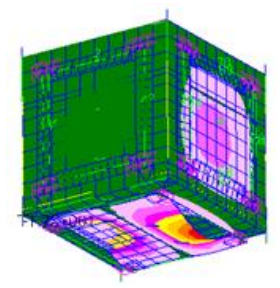

(b) $13^{\text {th }}$ Mode

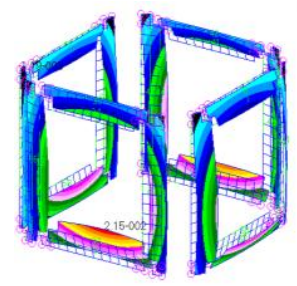

(c) $14^{\text {th }}$ Mode

Fig. 7. Mode shape.

TABLE V: QUASI-STATIC ANALYSIS RESULT SUMMARY

\begin{tabular}{l|l|l|l|l|l|l|l}
\hline \hline & \multicolumn{3}{|c|}{ Max Stress $(\mathrm{MPa})$} & \multirow{2}{*}{$\mathrm{SF}$} & \multicolumn{3}{|c}{ Margin of Safety } \\
\cline { 2 - 5 } \cline { 7 - 9 } & $\mathrm{x}$ & $\mathrm{y}$ & $\mathrm{z}$ & & $\mathrm{x}$ & $\mathrm{y}$ & $\mathrm{z}$ \\
\hline PCB & 18.3 & 16.7 & 6.51 & 1.40 & 8.45 & 9.35 & 25.6 \\
\hline Structure & 20.6 & 18.9 & 2.82 & 1.25 & 9.72 & 10.7 & 77.3 \\
\hline $\begin{array}{l}\text { CPV } \\
\text { System }\end{array}$ & 6.0 & 6.06 & 1.97 & 2.0 & 4.83 & 4.78 & 16.8 \\
\hline $\begin{array}{l}\text { MEMS } \\
\text { Thruster }\end{array}$ & 0.17 & 0.17 & 2.26 & 2.0 & 205 & 205 & 14.5 \\
\hline \hline
\end{tabular}

TABLE VI: PCB ANALYSIS RESULTS SUMMARY

\begin{tabular}{l|l|l|l}
\hline \hline PCB & $\delta_{\max }(\mathrm{mm})$ & $\delta_{\text {allowable }}(\mathrm{mm})$ & MoS \\
\hline EPS & 0.180 & 0.435 & 0.93 \\
\hline Communication & 0.180 & 0.307 & 0.36 \\
\hline Mother Board & 0.181 & 0.302 & 0.34 \\
\hline PPM & 0.162 & 0.344 & 0.70 \\
\hline GPS & 0.162 & 0.222 & 0.10 \\
\hline \hline
\end{tabular}

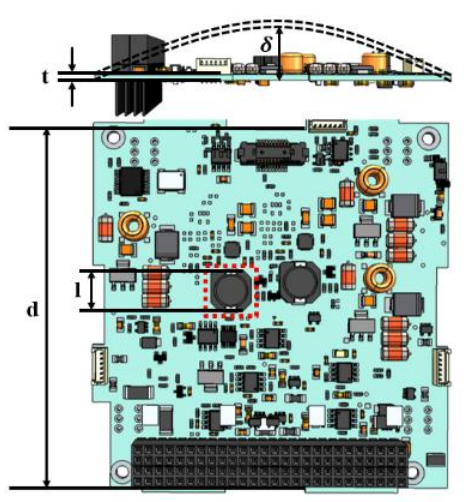

Fig. 8. EPS Board configuration. $(C=1.26, t=1.6 \mathrm{~mm}, r=0.8 \mathrm{~mm}, l=11.6 \mathrm{~mm}, d=90 \mathrm{~mm})$ 


\section{CONCLUSION}

A structural design concept of the STEP Cube Lab based on the $1 \mathrm{U}$ cube standard in order to achieve mission objectives has been proposed and investigated. For $1 \mathrm{U}$ CubeSat design, it is very important to achieve an efficient and lightweight satellite configuration under the constraint of limited CubeSat volume because the satellite will carry a number of payloads for on-orbit verification of technologies for future missions. The structural design, along with a novel non-explosive holding and release mechanism for synchronous release of multi-deployable antennas has been proposed and investigated. The effectiveness and validity of the structural design has been verified using quasi-static and modal analysis, as well as PCB analysis based on fatigue failure theory. The analysis results showed that the structural design of the STEP Cube Lab is effective for achieving mission objectives and guaranteeing structural safety under launch loads.

\section{ACKNOWLEDGMENT}

This research was supported by the Space Core Technology Development Program through the National Research Foundation of Korea (NRF) funded by the Ministry of Science, ICT and Future Planning (NRF-2012 M1A3A3A03033597).

\section{REFERENCES}

[1] H. Heidt, J. Puig-Suari, A. S. Moore, S. Nakasuka, and R. J. Twiggs, "CubeSat: A new generation of picosatellite," in Proc. the $14^{\text {th }}$ Annual AIAA/USU Conference on Small Satellites, Logan, UT, August 2001.

[2] R. D. Jenkins IV, "NPS-SCAT: systems Engineering and Payload Subsystems design integration and testing of NPS' First Cubesat," thesis, United States Naval Academy, June 2010.

[3] A. Thurn, S. Huynh, S. Koss, P. Oppenheimer, S. Butcher, J. Schlater, and P. Hagan, "A nichrome burn wire release mechanism for CubeSats," in Proc. the $41^{\text {st }}$ Aerospace Mechanisms Symposium, Jet Propulsion Laboratory, May 2012.

[4] J. R. Jung, G. I. Kim, S. J. Lee, and C. H. Kang, "Characteristics of the shock response spectrum for structures subjected to pyroshock," in Proc. J. of the Korean Society for Aeronautical \& Space Sciences Fall Conference, May 2010.

[5] M. H. Lee, J. H. Son, and H. S. Hwang, Shape Memory Alloy (SMA) Actuator Based Separation Device, European Space Agency, Special Publication, no. 653, 2011
[6] J. K. Lee and T. G. Kim, "MEMS solid propellant thruster array with micro membrane igniter," Sensors and actuators. A Physical, vol. 190, pp. 52-60, Feb. 2013.

[7] Y. Shimakawa, T. Yoshitake, Y. Kubo, T. Machida, K. Shinagawa, A. Okamoto, Y. Nakamura, A. Ochi, S. Tachikawa, and A. Ohnishi, "A variable-emittance radiator based on a metal-insulator transition of (La,Sr) $\mathrm{MnO}_{3}$ thin films," Applied Physics Letters, vol. 80, no. 25 , 2002.

[8] Y. Miyazaki, F. Polasek, and Akachi, "Oscillating Heat Pipes," SAE Technical Papers, vol. 2000, no. 1, 2000.

[9] K. Saito, Y. Abiko, K. Toya, K. Mori, Y. Kogetsu, and T. lwasaki, "Development of concentrator photovoltaic system," SEI Technical Review, no. 76, pp. 23-36, Apr. 2013.

[10] D. S. Steinberg, Vibration Analysis for Electronic Equipment, Wiley, Interscience publication, $3^{\text {rd }}$ edition, 2000.

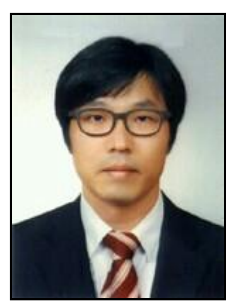

Hyun-Ung Oh received $\mathrm{PhD}$ in the Dept. of Aerospace Engineering at Tokyo University in 1999. $\mathrm{He}$ is currently an assistant professor in the Dept. of Aerospace Engineering at Chosun University, republic of Korea. His research interest is space system engineering, space mechanism using smart materials for space application, semi-active vibration control and space thermal control. He is a member of The Japan Society for Aeronautical and Space Sciences, The Korean Society for Aeronautical and Space Sciences, The Korean Society for Noise and Vibration Engineering and The Society for Aerospace System Engineering.

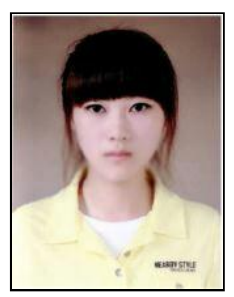

Su-Hyeon Jeon is the 4th undergraduate student in the Department of Aerospace Engineering at Chosun University. She is in charge of structure subsystem for STEP Cube Lab development. During cube satellite development, she carried out the structure design and structure analysis including PCB. Her research interest is space structure design and space mechanism using smart materials, structure analysis and vibration isolation for the space application.

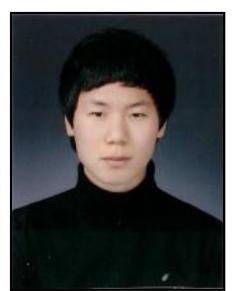

Sung-Cheol Kwon is currently pursuing the master degree in the Department of Aerospace Engineering at Chosun University. He is in charge of system engineer and team leader for STEP Cube Lab development. His research interest is energy harvesting, vibration control for space applications, structure analysis and space system engineering. He is a member of the Korean Society for Aeronautical and Space Sciences and The Korean Space Science Society. 